\title{
LA PANDEMIA DEL CORONAVIRUS Y SU IMPACTO SOBRE EL COMERCIO INTERNACIONAL:
}

\section{Una mirada sobre el mundo y Argentina}

Graciela Bonomelli *

\section{Resumen}

El presente texto plantea un análisis de la irrupción de la pandemia de coronavirus (COVID-19) en el mundo y su impacto en el comercio internacional. Se hace hincapié en la mirada de los principales referentes mundiales en materia económica, así como un énfasis sobre la Argentina y los cambios que provocarán a mediano plazo. Argentina

Palabras clave: Comercio Internacional- Coronavirus - Impacto Comercio-

\section{THE CORONAVIRUS PANDEMIC'S AND ITS IMPACT ON THE WORLD TRADE: A look at the world and Argentina}

\begin{abstract}
This text presents an analysis of the emergence of the coronavirus pandemic (COVID-19) in the world and its impact on the world trade. It emphasizes on the main world leader's view in economic matters as well as an emphasis on Argentina and the changes it will bring in the medium term.
\end{abstract}

Key words: World Trade- Coronavirus - Trade Impact- Argentina-

TRABAJO RECIBIDO: 02/05/2020 - TRABAJO ACEPTADO: 14/05/2020

\footnotetext{
* Dra. en Ciencia Política. Universidad Católica de Córdoba. Profesora Titular Cátedra de Comercio Exterior en la Licenciatura en RRII de la Facultad de Ciencia Política y RRII de la Universidad Nacional de Rosario. Correo electrónico:gbonomelli@gmail.com Se agradece la colaboración de la Lic. Sabrina Ravasio en las correcciones para su publicación.
} 
"Cuando China estornuda, el mundo se resfría”

\section{1- Mirando al Mundo:}

El surgimiento del coronavirus (COVID-19), primero como epidemia y luego como pandemia, generó que muchos países decretaran que su población se sometiera a cuarentena obligatoria, que se cerraran fronteras y que se restringieran actividades. A grandes rasgos, se paralizó el mundo.

Desde el punto de vista económico, el virus tendrá un fuerte impacto. Cualquier análisis parte desde la incertidumbre mientras no sepamos cuán grave será la letalidad de esta pandemia y la velocidad con la que se seguirá expandiendo. Si bien es difícil estimar su impacto, sabemos de antemano que el 2020 será un año sesgado por la recesión generalizada.

La crisis sanitaria ya impactó en la actividad económica global. En los dos primeros meses de 2020, la producción industrial china cayó por primera vez en treinta años. La mayoría de los analistas pronostican que el crecimiento económico del gigante asiático estará por debajo del 5 por ciento en el presente año (RUBINZAL, 2020).

La Organización para la Cooperación y el Desarrollo Económicos (OCDE) rebajó su pronóstico de crecimiento mundial del 2,9 al 2,4 por ciento, aunque advirtiendo que un "brote de coronavirus más largo e intenso" puede recortarlo al 1,5 por ciento. Si bien este crecimiento era tenue, afirma el Organismo, estaba estabilizándose cuando golpeó el COVID-19. Las restricciones sobre los movimientos de personas, bienes y servicios, y las medidas de contención aplicadas, como el cierre de fábricas, han hecho retroceder al sector industrial recortado la demanda interna en China. El impacto sobre el resto del mundo a través de los viajes de negocios y el turismo, las cadenas de suministro, las materias primas y la caída de la confianza, está agravándose (OCDE, 2020).

El Instituto de Finanzas Internacionales (IIF por sus siglas en inglés) -asociación de comercio global de instituciones financieras, creado en 1983 por treinta y ocho bancos de los principales países industrializados- planteó que este año se reducirá el crecimiento de China del 5,9 al 3,7 por ciento, y el de los Estados Unidos del 2 al 1,3 por ciento. El resto del mundo será inestable. La epidemia ha desatado la mayor fuga de capitales de los países emergentes desde que existen registros. El IIF calcula en 30.000 millones de dólares las salidas en el último mes y medio, cifra mayor que la registrada tanto en la crisis financiera global de 2008 como en las turbulencias de 2015 en China (en FARIZA, 2020).

En los últimos cien años el mundo ha sido testigo de siete pandemias -gripe española, asiática y de Hong Kong, H1N1, SARS, MERS y el ébola- que han traído efectos económicos tanto del lado de la oferta, como la súbita reducción de la fuerza laboral, como del lado de la demanda, o el contagio de los consumidores, restricciones a su movilidad y la tendencia de ahorrar dinero frente a la incertidumbre (OPERTTI y MESQUITA MOREIRA, 2020).

Como afirma Juan Pablo Marino, "el "cisne negro" que constituye el nuevo coronavirus ha vuelto a poner sobre la mesa debates que estaban postergados, ha acelerado otras discusiones y también ha propiciado la aparición de nuevas controversias sobre tópicos relacionados con las reglas económicas y financieras, el rol del Estado y del sector privado, las instituciones supranacionales, los criterios de 
integración, el comercio internacional, el consumo, la producción, las formas del trabajo, la digitalización, las desigualdades, entre otras" (MARINO, 2020).

Los impactos de las crisis pandémicas sobre comercio mundial y regional habían sido en su mayoría moderados, ya sea porque afectaron principalmente países de menor peso en la economía global o porque se logró limitar el contagio. El efecto de la actual crisis puede superar con creces los de la gripe española de 1918 que, a excepción de las demás pandemias, afectó las principales economías del mundo y de la región, con una reducción estimada de 10 por ciento del comercio mundial y de cerca de 20 por ciento de los intercambios regionales. Asimismo, la Gran Recesión de 2008-2009, que llevó a una caída histórica anual de 20 por ciento en el comercio mundial y latinoamericano, dejó en claro las implicancias que pueden tener estos cambios estructurales.

Pero al parecer esta vez es diferente. La crisis del coronavirus podría superar tanto a la gripe española como a la crisis financiera del 2008-2009 debido a la gran conectividad humana y comercial que hoy vivimos como consecuencia de la Gran Liberalización de la posguerra, menores costos de transporte y comunicación y el desarrollo de las cadenas globales de valor.

Como antesala de lo que viene, los primeros datos comerciales del 2020 son poco reconfortantes. China, el epicentro de la pandemia y de las cadenas globales de valor, vio caer sus exportaciones en un 17 por ciento y sus importaciones un 4 por ciento en el primer bimestre del 2020, comparado con ese mismo período el año anterior. En Estados Unidos, las importaciones totales y las provenientes de América Latina y el Caribe (ALC) también cayeron en enero, en un 4 por ciento y 2 por ciento en términos anuales, respectivamente, cuando apenas comenzaba la pandemia. En Brasil, las exportaciones del primer bimestre del año se redujeron un 8,5 por ciento, también en términos anuales. Estas cifras son alarmantes si se tiene en cuenta que el comercio mundial ya se encontraba en plena desaceleración: en 2019 creció apenas 1 por ciento, comparado con un promedio de 5 por ciento en las últimas dos décadas.

Según los datos históricos disponibles, esta es una crisis que podría afectar a todos los países de ALC, sin importar su nivel de especialización. Aunque los precios de commodities como el petróleo y cobre enfrenten mayor volatilidad, los bienes manufacturados también son muy vulnerables a paradas súbitas, por la dependencia de las cadenas de valor y ante la posibilidad de que se posterguen las compras por parte de los consumidores. Asimismo, el Banco Interamericano de Desarrollo estima que los servicios como el turismo se verán particularmente afectados por las medidas de contención como la disminución drástica de los vuelos, los cierres obligatorios de hoteles y el impacto de la enfermedad en su fuerza laboral (en OPERTTI y MESQUITA MOREIRA, 2020).

Para Marcelo Elizondo, especialista en negocios internacionales y profesor del Instituto Tecnológico de Buenos Aires y Director de la Consultora DNI, esta pandemia va a generar enormes cambios en el comercio internacional. Se transita hacia un mundo mucho más basado en requisitos cualitativos, lo que generará modificaciones en los procesos de producción. No advierte, sin embargo, una reversión de la globalización, porque al ser la economía y la cultura globales no se podría abastecer la demanda de 7.500 millones de personas sin producción a escala global. Pero sí identifica la aparición de nuevos requisitos que hagan de los negocios internacionales un proceso más complicado y exigente. El autor se imagina muchas nuevas normas sanitarias y de seguridad en los productos que se intercambien a nivel mundial (en MARINO, 2020). 
La Comisión Económica para América Latina y el Caribe (CEPAL) estima una contracción de $-1,8$ por ciento del producto interno bruto regional, lo que podría llevar a que el desempleo en la región suba en diez puntos porcentuales. De esta manera, de un total de 620 millones de habitantes, el número de pobres en la región subiría de 185 a 220 millones, en tanto que las personas en pobreza extrema podrían aumentar de 67,4 a 90 millones. Bárcena, Secretaria Ejecutiva de la CEPAL, precisó que el Coronavirus afectará a la región a través de cinco canales. Un primer canal de transmisión de esta crisis es el efecto de la disminución de la actividad económica de varios de los principales socios comerciales en las exportaciones de bienes de los países de la región. China, por ejemplo, es un destino importante para las exportaciones de varias economías latinoamericanas, siendo el principal socio comercial en los casos de Chile, Perú y Brasil. La Comisión estima que las exportaciones de la región a ese destino podrían caer hasta 10,7 por ciento en valor (CEPAL, 2020).

Un segundo canal proviene de la caída en la demanda de servicios de turismo, que impactaría más severamente a los países del Caribe. Se calcula que, si la prohibición de viajes a causa del virus se prolonga por uno, dos, o tres meses, la actividad turística en esa región específica, en 2020, se contraería en 8 por ciento, 17 por ciento y 25 por ciento, respectivamente.

Bárcena agregó que un tercer canal de transmisión se daría a través de la interrupción de las cadenas globales de valor. Esto afectaría principalmente a México y Brasil, países que importan partes y bienes intermedios desde China para sus sectores manufactureros -en especial en los casos de repuestos para automóviles, electrodomésticos, productos electrónicos y farmacéuticos.

Un cuarto canal que afectaría a la región de América Latina y el Caribe se vincula a la caída de los precios de los productos básicos, sobre todo para los países exportadores de materias primas en América del Sur. En tanto, un quinto canal de transmisión se deriva de la mayor aversión al riesgo de los inversionistas y el empeoramiento de las condiciones financieras globales, explicó. "Parte de estos efectos ya se aprecia en la fuerte disminución de los índices bursátiles en la región", indicó Bárcena (CEPAL, 2020).

Por su parte, el Director General de la Organización Mundial del Comercio (OMC), Roberto Azevêdo, subraya que en esta coyuntura pueden pasar dos cosas. O los flujos comerciales se diversifican y se redistribuyen para esquivar las restricciones procedentes de la pandemia y de alguna manera se centran en un área regional más limitada, o bien se cierran fronteras y se impulsa la producción doméstica. Pero, en su opinión, esto último sería un error ya que ningún país es autosuficiente, por lo que elevar más barreras no sería la solución. Una de las tesis de la OMC es que no basta con tener capacidad para producir algo, sino que hay que ser buenos en ello: de ahí la necesidad ineludible del comercio (en SANDRI, 2020).

La OMC prevé un desplome de 32 por ciento en el comercio global de bienes para este año por causa de la pandemia por coronavirus, antes de un probable repunte en 2021. El estudio del Organismo proyecta un rebote de entre 21 por ciento y 24 por ciento para el próximo año, sin embargo, aclaran que el resultado dependería en gran medida del tiempo que dure el brote y, sobre todo, de la efectividad de las medidas que tomen los gobiernos (OMC, 2020). 


\section{2- Mirando a Argentina:}

Un fuerte deterioro en el frente financiero y en el comercio internacional junto a una parálisis del consumo y la producción en aquellos países donde parte relevante de su población está en cuarentena, son las consecuencias económicas más evidentes de la pandemia del coronavirus.

Argentina no escapa a esta realidad. Por una parte, caen los precios y los volúmenes del comercio de commodities: el país exportaba 6.000 millones de dólares de productos de la cadena productiva basada en animales, 25.000 millones de dólares en la de vegetales, 12.000 millones de dólares de alimentos con alguna elaboración y 4.000 millones de dólares de commodities minerales. Por otro lado, Marcelo Elizondo sostiene que se sumará a lo referido el impacto que genere el freno que sufran las economías de China y la Unión Europea -los dos focos mayores de la pandemia hasta abril de 2020cuyos mercados son muy relevantes para nuestras ventas externas: la Unión Europea compra casi 9.000 millones de dólares anuales desde Argentina, y China lo hace por casi 7.000 millones de dólares (en KANTOR, 2020).

Según afirma Diego Rubinzal (2020), este shock externo negativo afectará la economía del país a través de tres modalidades diferentes:

1. Impacto comercial: la reducción de la demanda mundial y del precio de los commodities implica menor ingreso de divisas. Los últimos datos estadísticos revelan una retracción de las exportaciones argentinas de porotos de soja y derivados, carnes, vinos y congelados al mercado chino. Otra fuente de divisas que caerá es el turismo receptivo.

2. Impacto financiero: los capitales que salieron desde las economías emergentes hacia los desarrollados ya superaron los 60.000 millones de dólares desde comienzos de 2020. Es el valor más elevado, para el mismo período, desde la crisis financiera internacional en 2008. Ese "vuelo a la calidad" genera presiones devaluatorias en las monedas periféricas.

3. Impacto en las inversiones: la baja de precio del petróleo sepulta, por lo menos en el corto plazo, las proyecciones que se realizaban para la explotación de Vaca Muerta.

Según un nuevo informe de la Bolsa de Comercio de Rosario, del lado del comercio internacional, "(..) entre los países afectados por el brote COVID-19 China es un caso paradigmático para la Argentina ya que es el destino de casi el 90 por ciento de nuestras exportaciones de poroto de soja -que aportaron cerca de 3.000 millones de dólares en el 2019-, el 70 por ciento de las carnes bovinas -por más de 2.000 millones de dólares- y el 22 por ciento de la carne porcina -con un valor de 3.500 millones de dólares en el 2019-. En Brasil, nuestro principal socio comercial y termómetro de lo que puede esperarse para la actividad económica local, la participación del gigante asiático en las exportaciones es incluso más alta, estimándose que se deterioren sus perspectivas de crecimiento para este 2020" (en ORIGLIA, 2020).

Adicionalmente sufrirán los volúmenes embarcados principalmente por la menor demanda de China, segundo mayor mercado para Argentina en el planeta, pero principal cliente de agroexportaciones, cuestión que resulta inexorable.

En 2019 China importó 7.000 millones de dólares desde la Argentina y dos tercios de esa cifra se debió al complejo sojero: del total, 3.600 millones de dólares fueron productos primarios y 3.000 millones de dólares, manufacturados de origen 
agropecuario. Adicionalmente, hoy las carnes también tienen en China su principal mercado. Asia, que es un foco crítico del problema sanitario, es para la Argentina más relevante comercialmente que Europa con 21.000 millones de dólares exportados en 2019.

La creciente problemática en Europa con epicentro en Italia y España, pero con capacidad de afectar a toda la economía continental, también podría impactar en las exportaciones argentinas -más de 10.000 millones de dólares exportados a toda Europa, y unos 8.800 millones a la Unión Europea-, que en su mayoría se componen de productos de origen agropecuario y alimentos -alrededor de 5.500 millones de dólares.

Por propiedad transitiva Brasil, principal cliente de la Argentina en el mundo las exportaciones del año pasado a ese país alcanzaron 10.500 millones de dólares-, está fuertemente expuesto a China y a la Unión Europea. Una consecuente desaceleración de la economía brasileña implicará menos importaciones desde la Argentina, que es el cuarto mayor proveedor de Brasil en el mundo.

Si a este panorama sumamos la decisión del Gobierno de Alberto Fernández de salirse de la mesa de negociación de acuerdos de libre comercio del Mercosur, indefectiblemente producirá que, si los otros socios del bloque avanzan, se dará un quiebre de hecho de la unión aduanera.

Según analiza Javier Lewkowicz, hay al menos cuatro factores bien nítidos que influenciaron en la salida de la Argentina de la mesa de negociación. El primero tiene que ver con los antecedentes, ya que como la administración de Mauricio Macri promovió los acuerdos de libre comercio, la negociación en la que entró el nuevo gobierno estaba relativamente avanzada, con ofertas sobre la mesa y lobby de todos los sectores. En segundo lugar, Brasil, el otro puntal dominante del bloque, tiene un gobierno ultraliberal que pretende avanzar a toda velocidad con los acuerdos. En este contexto, la posición de Jair Bolsonaro implicó un quiebre del diálogo histórico entre ambos países. En tercer lugar, la crisis en la que ya venía sumergida la economía argentina sumado a la pandemia ofrece un contexto que difícilmente sea peor para encarar una apertura de la economía. Además, el gobierno está completamente abocado a la gestión de la crisis del coronavirus y considera que no están dadas las condiciones para presentar una oferta de liberalización de aranceles consultada previamente con el sector privado. En cuarto lugar, Uruguay, con el apoyo de Brasil y el sostén más tímido de Paraguay, adoptó una posición muy ofensiva e impidió introducir nuevas instancias para dilatar un poco las conversaciones (LEWKOWICZ, 2020).

$\mathrm{Si}$ bien la retórica integradora se mantuvo en su lugar, las fricciones entre Argentina y sus socios estallaron negativamente. La nueva administración argentina se diferenció ideológicamente y se suspendió toda coordinación económica y política.

\section{Conclusiones}

El coronavirus hunde al comercio mundial y pone en riesgo la globalización. No es un freno al comercio como estamos acostumbrados a ver desde hace algunas décadas, sino un verdadero colapso del intercambio mundial. Es un punto de inflexión que nos invita a revisar nuestros propios modelos productivos para afrontar un mundo totalmente diferente. Es evidente que el volumen de las exportaciones e importaciones caerá y no será posible mantener el comercio con el modelo que estábamos acostumbrados a comerciar. 
Se tratará en adelante, más que nunca, de no ir al mundo solo a veces sino con continuidad, de cuidar la relación con el mundo comercial, usar y/o desarrollar nuevas tecnologías para integrarse en redes, desarrollar estándares más exigentes en el diseño y seguridad de productos al acompañar tendencias globales, y lograr una reputación que nos permita mantenernos en un flujo comercial mucho más acotado.

El mundo transita una encrucijada y el comercio y la cooperación internacional serán actores centrales que permitan re-pensar cómo seguir insertos internacionalmente y cómo recuperar nuestra capacidad de contribuir a un desarrollo sostenible. A pesar de las dificultades que nos esperan, los países necesitan más, y no menos, multilateralismo, porque el mundo se ha vuelto más interdependiente que nunca.

Ojalá podamos revisar el desacierto de salirnos de las negociaciones comerciales extra-bloque, ya que el nuevo orden comercial requerirá de espacios para salir a negociar en forma conjunta en un mundo mucho más disruptivo del que conocíamos.

El COVID-19 aceleró tendencias que ya venían observándose en el comercio mundial, tales como el comercio de servicios, las prácticas virtuales o la exacerbación del desarrollo del mundo comercial de lo intangible. Esta tendencia irá en aumento en los próximos años y nos invitará a acostumbrarnos a vivir y competir en un mundo del e-commerce, de ferias virtuales, de cambios en el marketing donde el trabajo incluya cada vez más a las nuevas tecnologías en un mundo muy inestable.

En este escenario la globalización será mucho más complicada, quizás con menores volúmenes de comercio, pero con más valor. Tenemos delante un mundo donde el regionalismo no será necesariamente geográfico, sino quizás priorizando patrones culturales comunes y de confluencias culturales.

Como afirma Albert Camus en su novela "La Peste”, “(...) algo que se aprende en medio de las plagas: que hay en los hombres más cosas dignas de admiración que de desprecio (...)" (CAMUS, 1947:178). Bregamos para que el mundo pueda usar las cosas dignas que siempre fueron admiradas en el hombre para renacer en un comercio global más eficiente, legítimo y justo.

\section{Bibliografía}

BANCO INTERAMERICANO DE DESARROLLO (2020), Impacto del coronavirus en el comercio y la integración: ¿qué hacer?, por OPERTI, F. y MESQUITA MOREIRA, M., Disponible en: https://blogs.iadb.org/integracioncomercio/es/coronavirus-comercio-integracion/. Consulta: 27 de marzo de 2020.

CAMUS, A. (1947), La Peste, Ed. Lelibros. Disponible en: https://lelibros.online/libro/descargar-libro-la-peste-en-pdf-epub-mobi-o-leer-online/. Consulta: abril de 2020.

COMISION ECONOMICA PARA AMERICA LATINA Y EL CARIBE (2020), COVID-19 tendrá graves efectos sobre la economía mundial e impactará a los países de América Latina y el Caribe. Comunicado de Prensa. Disponible en: https://www.cepal.org/es/comunicados/covid-19-tendra-graves-efectos-la-economiamundial-impactara-paises-america-latina. Consulta: el 27 de marzo de 2020. 
FARIZA, I. (9 de marzo, 2020), La epidemia desata, en un mes y medio, la mayor fuga de capitales de los emergentes desde que hay registros, El País. Disponible en línea: https://elpais.com/economia/2020-03-09/el-coronavirus-provoca-la-mayor-fugade-capitales-de-los-paises-emergentes-desde-que-hay-datos.html. Consulta: 20 de marzo de 2020.

KANTOR, D. (13 de marzo de 2020), El costo del coronavirus en la Argentina: se perderían US\$3.400 millones sólo por exportaciones, Clarín. Disponible en: https://www.clarin.com/economia/costo-coronavirus-argentina-perderian-us-3-400millones-solo-exportaciones_0_u0dk4DN3.html. Consulta: 27 de marzo de 2020.

LEWKOWICZ, J. (28 de abril, 2020), El Mercosur cerca de la ruptura, Pagina 12. Disponible en: https://www.pagina12.com.ar/262467-el-mercosur-cerca-de-laruptura. Consulta: 24 de abril de 2020.

MARINO, J. P. (25 de marzo, 2020), Coronavirus: cómo se reconfigura la economía mundial después de la pandemia, Ambito.com. Disponible en línea: https://www.ambito.com/ambito-biz/estado/coronavirus-como-se-reconfigura-laeconomia-mundial-despues-la-pandemia-n5090925. Consulta: 25 de marzo de 2020.

ORGANIZACIÓN MUNDIAL DEL COMERCIO (2020), Coronavirus y comercio mundial. Disponible en: https://www.wto.org/spanish/tratop_s/covid19_s/covid19_s.htm. Consulta: 30 de abril de 2020.

ORGANIZACIÓN PARA LA COOPERACIÓN Y EL DESARROLLO ECONÓMICOS (2020), Graves efectos del brote de COVID-19 sobre las perspectivas económicas. Disponible en: http://www.oecd.org/perspectivas-economicas/marzo2020/\#resources. Consulta: 30 de abril de 2020.

ORIGLIA, G. (12 de marzo, 2020), Coronavirus. El impacto en las exportaciones y en el ingreso de divisas a la Argentina, Diario La Nación. Disponible en: https://www.lanacion.com.ar/economia/comercio-exterior/coronavirus-el-impactoexportaciones-ingreso-divisas-argentina-nid2342331. Consulta: 23 de marzo de 2020.

RUBINZAL, D. (22 de marzo, 2020), El costo Económico de la pandemia. Diario Página 12. Disponible en: https://www.pagina12.com.ar/254004-el-costo-economico-dela-pandemia. Consulta: 27 de marzo de 2020.

SANDRI, P.M., (9 de abril, 2020), El coronavirus hunde el comercio mundial y pone en riesgo la globalización. Diario LA VANGUARDIA. Disponible en: https://www.lavanguardia.com/economia/20200409/48393983083/coronavirus-comerciomundial-globalizacion.html. Consulta: 30 de abril de 2020. 